This item was submitted to Loughborough's Research Repository by the author.

Items in Figshare are protected by copyright, with all rights reserved, unless otherwise indicated.

\title{
Processing and characterization of bio-polyester reactive blends: From thermoplastic blends to cross-linked networks
}

PLEASE CITE THE PUBLISHED VERSION

https://doi.org/10.1016/j.polymer.2017.10.069

\section{PUBLISHER}

(C) Elsevier

VERSION

AM (Accepted Manuscript)

\section{PUBLISHER STATEMENT}

This work is made available according to the conditions of the Creative Commons Attribution-NonCommercialNoDerivatives 4.0 International (CC BY-NC-ND 4.0) licence. Full details of this licence are available at: https://creativecommons.org/licenses/by-nc-nd/4.0/

\section{LICENCE}

CC BY-NC-ND 4.0

\section{REPOSITORY RECORD}

Nocita, Davide, Giuseppe Forte, Stavros Drakopoulos, Annamaria Visco, Alberto Giamporcaro, and Sara Ronca. 2017. "Processing and Characterization of Bio-polyester Reactive Blends: From Thermoplastic Blends to Cross-linked Networks". figshare. https://hdl.handle.net/2134/27540. 


\title{
Processing and characterization of bio-polyester reactive blends: from thermoplastic blends to cross-linked networks.
}

\author{
Davide Nocita $^{\mathrm{a}^{*}}$, Giuseppe Forte ${ }^{\mathrm{b}}$, Stavros X. Drakopoulos ${ }^{\mathrm{b}}$, Annamaria Visco ${ }^{\mathrm{a}}$, Alberto \\ Gianporcaro $^{\mathrm{a}}$, Sara Roncab \\ ${ }^{a}$ Department of Engineering, University of Messina, Contrada di Dio 1, 98166, Messina, Italy \\ ${ }^{b}$ Department of Materials, Loughborough University, Loughborough, Leicestershire, UK \\ * Corresponding author
}

\begin{abstract}
The addition of ethyl ester L-lysine tri-isocyanate (LTI) to mixtures of poly(lactide)/poly( $\varepsilon^{-}$ caprolactone) has been reported to improve the compatibility of the resulting blends. In the present work, we have investigated the influence of adding increasing amounts of LTI to the mechanical and thermal properties of the blends. Torque trends, plate-plate rheology, differential scanning calorimetry, scanning electron microscopy, and uniaxial tensile characterization were conducted on samples with amounts of LTI comprised between 0.5 and 5 phr. Results suggests that by increasing the content of LTI over 0.5 phr the mechanical and thermal behaviour of the blends tend to change from that of a thermoplastic to that of a cross-linked, rubber-like material with outstanding mechanical properties. Morphological investigations show a very fine, well-dispersed morphology in all cases. Numerical models have been applied to rheological experiments to identify processes and phases in the studied blends, further supporting the hypothesis of a cross-linked phase formed for blends containing more than 0.5 phr of LTI.
\end{abstract}

\section{Introduction}

In recent years the growing interest into bio-based polymers for environmental and medical applications has brought the need for new types of materials which can show outstanding physical properties, while maintaining the bio-integration ${ }^{1}$.

Most of the commercial grades of bio-polymers available nowadays show mechanical properties which are still not ideal for orthopaedics applications. Metals continue to be widely used in this sector, although polymeric material with proper elasticity and mechanical characteristics, able to dissolve in a biological medium and to selectively deliver drugs, could represent a useful alternative $^{1 \mathrm{~b}}$. 
A widely used method to tailor materials properties making use of what is commercially available is melt blending, and several studies have been devoted to the issue of obtaining properly dispersed blends using diverse combinations of polymers ${ }^{2}$. Polyesters, such as polylactide (PLA) and poly( $\varepsilon$ caprolactone) (PCL),are good examples as they couple interesting mechanical/thermal properties with biocompatibility and biodegradability.

Poly(lactide) is obtained by ring-opening polymerization of the $(\mathrm{D}, \mathrm{L})$ enantiomorphs of lactide, it is brittle at room temperature, as its $\mathrm{T}_{\mathrm{g}}$ is $\sim 60^{\circ} \mathrm{C}$, but shows suitable mechanical features like high yield strength and Young's modulus. Since lactides are sugars fermentation products, another great advantage is that the polymer can be obtained from $100 \%$ renewable sources ${ }^{1 \mathrm{~b}, 1 \mathrm{~d}}$.

Poly( $\varepsilon$-caprolactone) is instead a rubbery and very ductile material $\left(\mathrm{T}_{\mathrm{g}} \sim-60{ }^{\circ} \mathrm{C}\right.$ ), with over $1500 \%$ of ultimate strain and $~ 200 \mathrm{MPa}$ elastic modulus ${ }^{1 \mathrm{~b}, 1 \mathrm{c}}$.

They are both frequently used, either pure or in blends, in particular in the medical field, where they have found applications such as scaffolds for cellular growth, and sutures ${ }^{3}$.

Achieving a good dispersion of one phase in another is key to blending, since the properties of the final materials are expression of the interface characteristics ${ }^{1 \mathrm{~b}, 1 \mathrm{~d}, 2,4}$.

Many studies have targeted the dispersion of these polyesters, for example using block and random copolymers as additives during mixing, which brought more ductile materials with noticeable properties $^{1 \mathrm{a}, 4 \mathrm{a}, 4 \mathrm{~b}, 4 \mathrm{c}}$.

In multiphasic systems, the viscoelasticity of the interface is an important parameter, as it influences the macroscopic properties of the materials.

The linear viscoelastic properties obtained from rheological experiments can be used to infer the homogeneity and the phase dispersion of the materials, as a result of the presence of an interfacial area (and consequently interfacial tension) between the polyesters.

Previous studies on PLA/PCL blends reported that materials without a fine dispersion of the two components show an enhancement in the elastic modulus in the frequency region below $1 \mathrm{~Hz}$, that has been attributed to the shape relaxation of the dispersed phase due the presence of the interface ${ }^{5}$. Reactive mixing, i.e. the use of reagents able to produce reactive compounds chemically similar to the two phases during the mixing stage, has been reported as a successful method to obtain a fine dispersion and good interfacial characteristics in blends ${ }^{1 \mathrm{a},} 4^{\mathrm{d}, 4} 4^{\mathrm{e}, 6}$. Reactive agents based on aminoacid derivatives have been studied to produce co-polyester-urethane networks ${ }^{3,}{ }^{7}$ or in polyester blends obtained by reactive mixing or extrusion $1^{\mathrm{d},} 4^{\mathrm{e},} 6^{\mathrm{b},} 6^{\mathrm{c}}$.

Ethyl ester L-lysine tri-isocyanate (LTI) is a three-functional molecule, able to react with the hydroxyl chain ends of polyesters, generating grafted and cross-linked co-polyester-urethanes structures $^{1 \mathrm{~d}, 1 \mathrm{e}}$. 
The maximum amount of the reactive agent used till now, as found in the literature, is 2 phr $^{4 e, 4 f, 6 b}$ : Tuba et al. have investigated the increased ductility of the blends, while. Takayama et al. conducted annealing experiments of the reactive blends after processing, obtaining further improvements in both ductility and impact strength.

To the best of our knowledge, none of those studies employing LTI as a reactive agent has focused on the reaction mechanisms, to elucidate how the cross-linking density influences the mechanical properties and the viscoelastic interfacial characteristics of these reactive polyester-based blends.

We have previously reported that reactive blends of poly(lactide), poly(e-caprolactone) and LTI can show outstanding mechanical features and a range of applicability ${ }^{1 \mathrm{~b}}$.

In the present work, combining rheology, differential scanning calorimetry, uniaxial tensile, and electronic microscopy, we have analysed the influence of increasing amounts of LTI up to 5 phr on blends of PLA/PCL. Results suggest that high amounts of reactive agent ( $>0.5 \mathrm{phr})$ can lead to a different kind of material, which is still retaining some of the properties of the base polyesters, while showing a proper cross-linked, rubber-like behaviour. Further confirmation of the existence of this cross-linked phase is obtained from rheological data.

The dynamic rheological behavior of the reactive blends has been modelled using frequency dependent computational formulae. The fractional calculus was introduced to relate stress to strain fields describing viscoelastic phenomena ${ }^{8}$. To describe the experimental data of materials which exhibit symmetrical loss peak behavior or contain symmetrical distinct processes in the frequency spectrum, the Cole-Cole or four-parameter fractional derivative Zener function model can be applied $^{9}$. In addition, to fit asymmetrical processes the five-parameter fractional derivative Zener model has proven to be useful ${ }^{10}$. Similar semi-empirical mathematical formulae have been employed previously to model the dielectric response of materials including asymmetrical processes $^{11}$.

\section{Experimental}

\subsection{Materials and methods}

Poly(lactide) (Bioflex F6510, $M_{\mathrm{n}}=40000 \mathrm{~g} / \mathrm{mol}, M_{\mathrm{w}}=160000 \mathrm{~g} / \mathrm{mol}$ by GPC, supplied by FKUR) and Poly( $\varepsilon$-caprolactone) $\left(M_{\mathrm{n}}=100000 \mathrm{~g} / \mathrm{mol} ; \mathrm{M}_{\mathrm{w}}=160000 \mathrm{~g} / \mathrm{mol}\right.$ by GPC, supplied by SigmaAldrich) pellets were dried overnight before use.

Ethyl ester L-lysine tri-isocyanate (optical purity 80\%, supplied by Infine Chemicals) in liquid form was used as received. Physical and reactive blends were obtained by blending with an internal mixer, a Brabender Plasticorder PL-2000, following conditions previously described in 1b: 
- $\quad$ Polyesters pellets previously weighted and mixed in a glass beaker, were added in the mixer chamber at $180{ }^{\circ} \mathrm{C}$ and $25 \mathrm{rpm}$, at a constant ratio of 50:50 (wt\%)

- $\quad$ After 5 minutes of mixing, LTI (amounts comprised between 0,5and 5 phr) was added to the blends, keeping the processing conditions constant for further 10 minutes.

- $\quad$ During the mixing process, torque values expressed in $\mathrm{N}^{*} \mathrm{~m}$ were recorded every $30 \mathrm{~s}$ by the Brabender software on a PC interfaced with the instrument transducer.

- $\quad$ Materials obtained were compression moulded at $180^{\circ} \mathrm{C}$ and 100 bars for 10 minutes with a Campana s.r.l press, equipped with a water cooling system, to obtain flat sheets of $1 \mathrm{~mm}$ thickness.

All blends produced have been detailed and codified as reported in Table 1:

Table 1 - Blends code and composition

\begin{tabular}{|l|l|l|l|}
\hline Code & $\begin{array}{l}\text { PLA } \\
\text { (wt. \%) }\end{array}$ & $\begin{array}{l}\text { PCL } \\
\text { (wt. \%) }\end{array}$ & $\begin{array}{l}\text { LTI } \\
\text { (phr) }\end{array}$ \\
\hline T0 & 50 & 50 & 0 \\
\hline T05 & 50 & 50 & 0,5 \\
\hline T1 & 50 & 50 & 1 \\
\hline T2 & 50 & 50 & 2 \\
\hline T5 & 50 & 50 & 5 \\
\hline
\end{tabular}

Dog bones for tensile characterization were obtained by a Ray-Ran manual die cutter, following the ASTMD638-10. Type V specimens were characterized with a Lloyd LR 10K Uniaxial machine with a cross-head speed of $10 \mathrm{~mm} / \mathrm{min}$ according to the same standard. The mechanical parameters obtained from uniaxial tests are: Young modulus (E, MPa), stress at yielding ( $\left.\sigma_{\mathrm{y}}, \mathrm{MPa}\right)$ stress at break ( $\left.\sigma_{\mathrm{b}}, \mathrm{MPa}\right)$, maximum stress ( $\left.\sigma_{\mathrm{max}}, \mathrm{MPa}\right)$, elongation at yielding $\left(\varepsilon_{\mathrm{y}}, \%\right)$ and at break $\left(\varepsilon_{\mathrm{b}}, \%\right)$, and work at break $\left(\mathrm{W}_{\mathrm{b}}, \mathrm{J}\right)$.

Samples for scanning electron microscopy were obtained by cryogenical fracture in Liquid Nitrogen, in order to investigate the dispersion of the phases before and after rheological analysis. The as-compressed materials were characterised with a FEI Quanta FEG 450 microscope, operating at an accelerating voltage of $5 \mathrm{kV}$ in low vacuum mode, while the samples after rheology were analysed using a JEOL 7800F Field Emission Scanning Electron Microscope at 5kV.

Calorimetric characterizations were performed via differential scanning calorimetry with a TA Instruments DSC Q100, using $5 \mathrm{mg}$ samples subject to temperature ramps from room temperature 
to $200^{\circ} \mathrm{C}$, ata heating rate of $10^{\circ} \mathrm{C} / \mathrm{min}$. The crystalline degree of PCL, $\chi$, was calculated using equation (1):

$$
\chi=\frac{\Delta H_{m}}{\varphi \cdot \Delta H_{0}}
$$

Where $\Delta \mathrm{H}_{\mathrm{m}}[\mathrm{J} / \mathrm{g}]$ is the melting enthalpy as derived from the DSC traces, $\varphi$ is the weight fraction of the PCL and $\Delta \mathrm{H}_{\mathrm{o}}[\mathrm{J} / \mathrm{g}]$ is the theoretical enthalpy of fusion of a $100 \%$ crystalline PCL ${ }^{6 \mathrm{~b}}$. Initial crystalline fraction of PLA, $\chi_{\mathrm{i}}$, was calculated using equation (2):

$$
\chi_{i}=\frac{\Delta H_{m}-\Delta H_{c c}}{\varphi \cdot \Delta H_{0}}
$$

Where $\Delta \mathrm{H}_{\mathrm{cc}}[\mathrm{J} / \mathrm{g}]$ is the "cold-crystallization" enthalpy of PLA. Cold crystallization is due to the well-known phenomenon of PLA re-organization in more ordered regions induced by the thermal heating during a DSC test ${ }^{6}$. For this reason, equation 3 has been used to calculate the crystalline degree of the cold crystallized PLA $\left(\chi_{\mathrm{cc}}\right)$ :

$$
\chi_{c c}=\frac{\Delta H_{c c}}{\varphi \cdot \Delta H_{0}}
$$

Rheology experiments were conducted on an ARES LS2 by TA Instruments equipped with $25 \mathrm{~mm}$ plate-plate geometries. A temperature ramp experiment was initially conducted from room temperature to $200{ }^{\circ} \mathrm{C}$ at $10 \mathrm{rad} / \mathrm{s}$ and $0.1 \%$ strain, followed by strain amplitude oscillation, at 10 $\mathrm{rad} / \mathrm{s}$ and $150{ }^{\circ} \mathrm{C}$ from 0.1 to $10 \%$ of strain. The limit of the linear viscoelastic region was found to be $0.8 \%$ of strain for all blends and this limit was used for the other experiments. The thermal response with time was evaluated by applying $0.8 \%$ strain at $10 \mathrm{rad} / \mathrm{s}$ for $10^{5} \mathrm{~s}$ at $150{ }^{\circ} \mathrm{C}$. During this experiment, a build-up of the elastic modulus $\mathrm{G}^{\prime}$ was observed. Once the $\mathrm{G}^{\prime}$ reached a plateau value, the frequency response was evaluated at $150{ }^{\circ} \mathrm{C}, 0.8 \%$ of strain from 400 to $10^{-2} \mathrm{rad} / \mathrm{s}$.

\section{Results and discussion}

\subsection{Torque characterization}

The graph in Figure 1 shows the torque vs time trends of physical (T0) and reactive blends (T05T5), as recorded during the mixing process. 


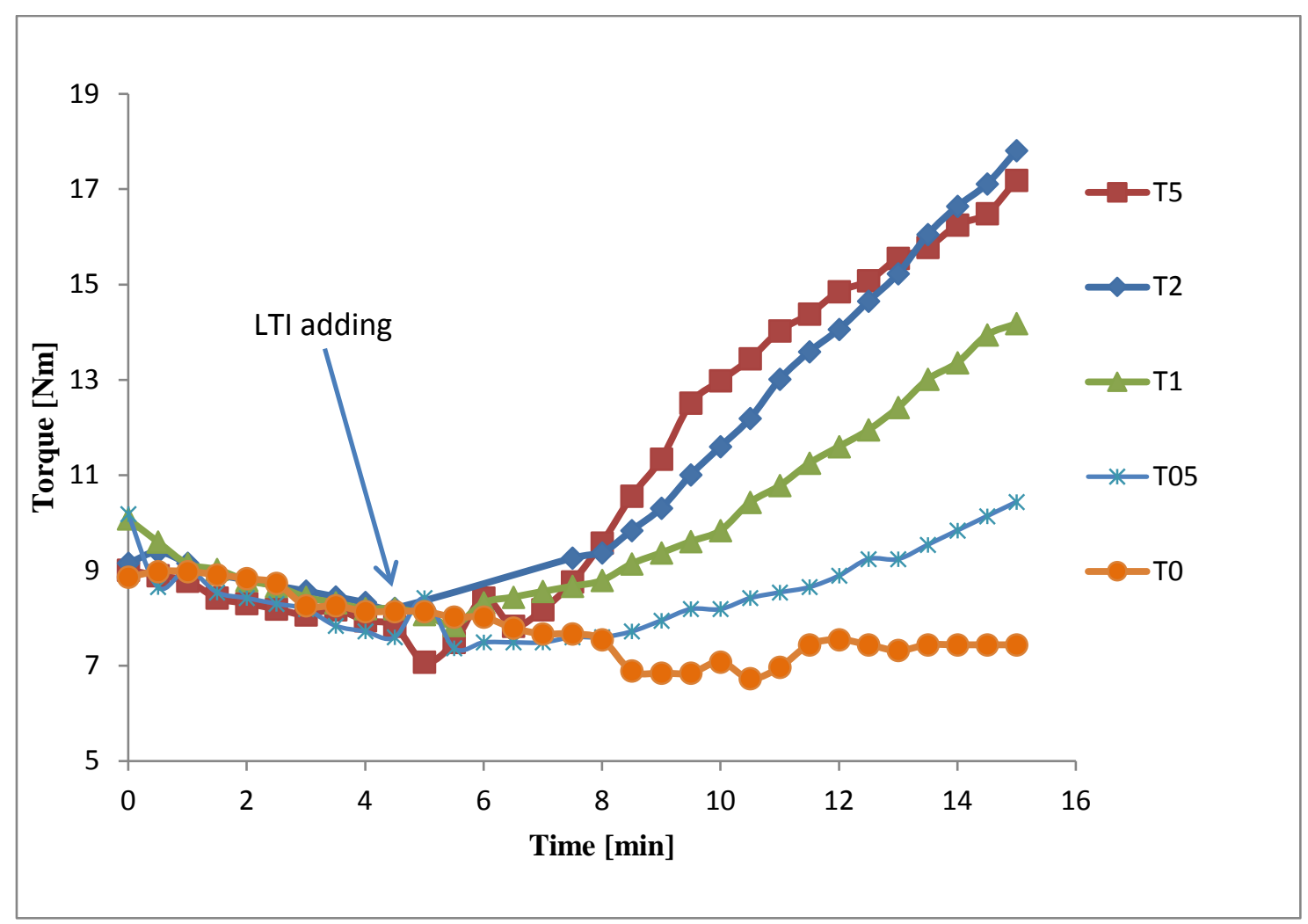

Figure 1. Torque vs time trends of Physical and Reactive blends

The torque is strictly related to the viscosity $\eta$ of the molten materials and this, in turn, is associated to their molecular weights, as suggested by Berry and Fox for any molecular weight $M$ higher than a critical value $M_{\mathrm{c}}$, defined as double the mass between entanglements, $M_{\mathrm{e}}{ }^{12}$ :

$\eta \propto M^{\alpha} ; \quad \alpha=3.4$

The torque values show a considerable increase, in some cases to double the initial values, in the presence of LTI ${ }^{12 b}$. According to Harada et al., the reactive mixing process in presence of LTI can produce copolyester-urethane networks, which localize at the interface between the polyesters, bringing to a finer dispersion of phases ${ }^{1 \mathrm{~d}, 1 \mathrm{e}}$.

The torque results support the idea that new branched and/or cross-linked structures of co-polyesterurethanes are formed during processing.

As shown in Figure 2, the reaction of LTI with PLA and PCL brings branched structures, thanks to the three-functionality of the reactive agent. 


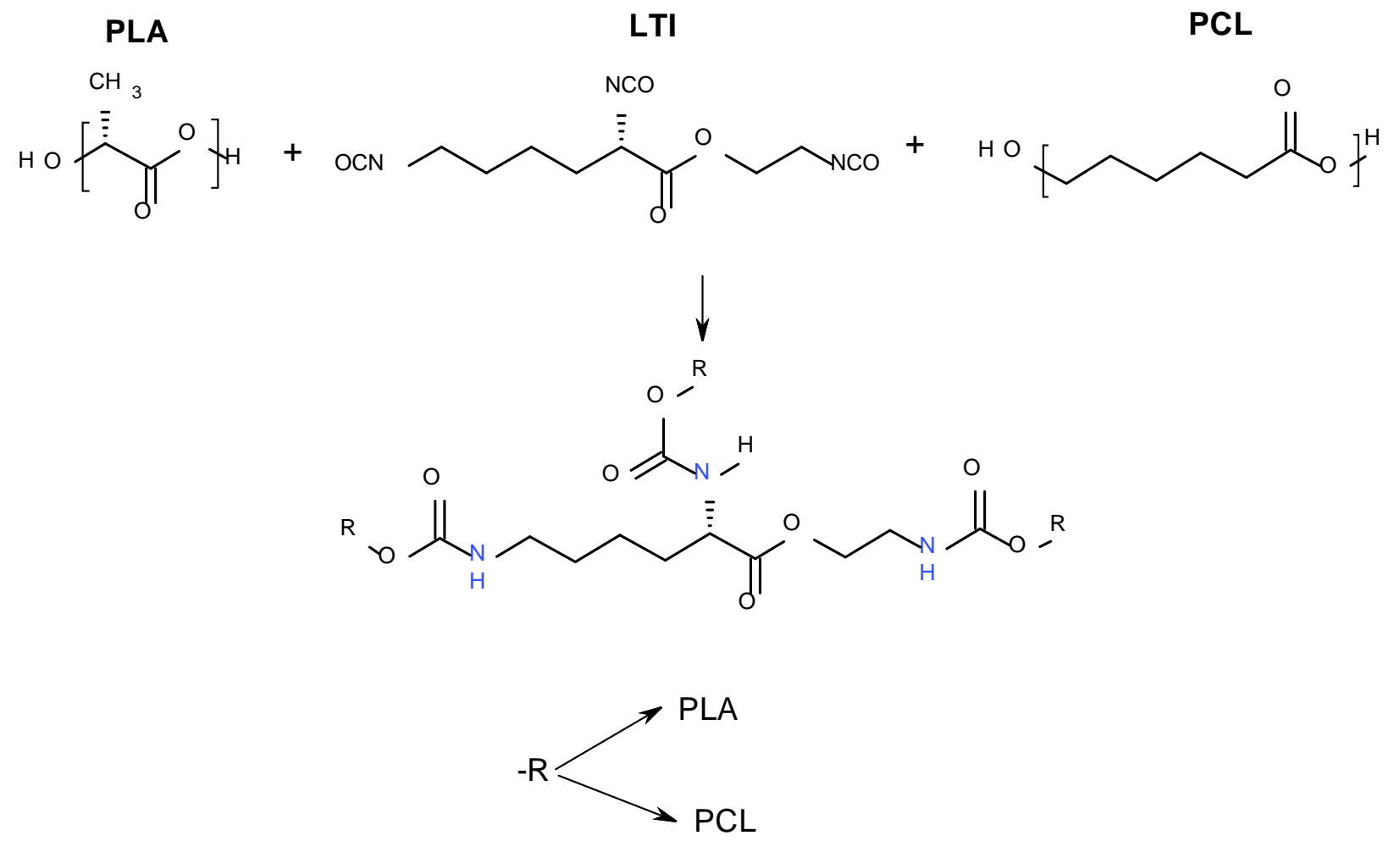

Figure 2. The reaction between PLA/PCL and LTI resulting in a combination of branched copolymer and (at higher content) network formation. 


\subsection{Tensile characterization}

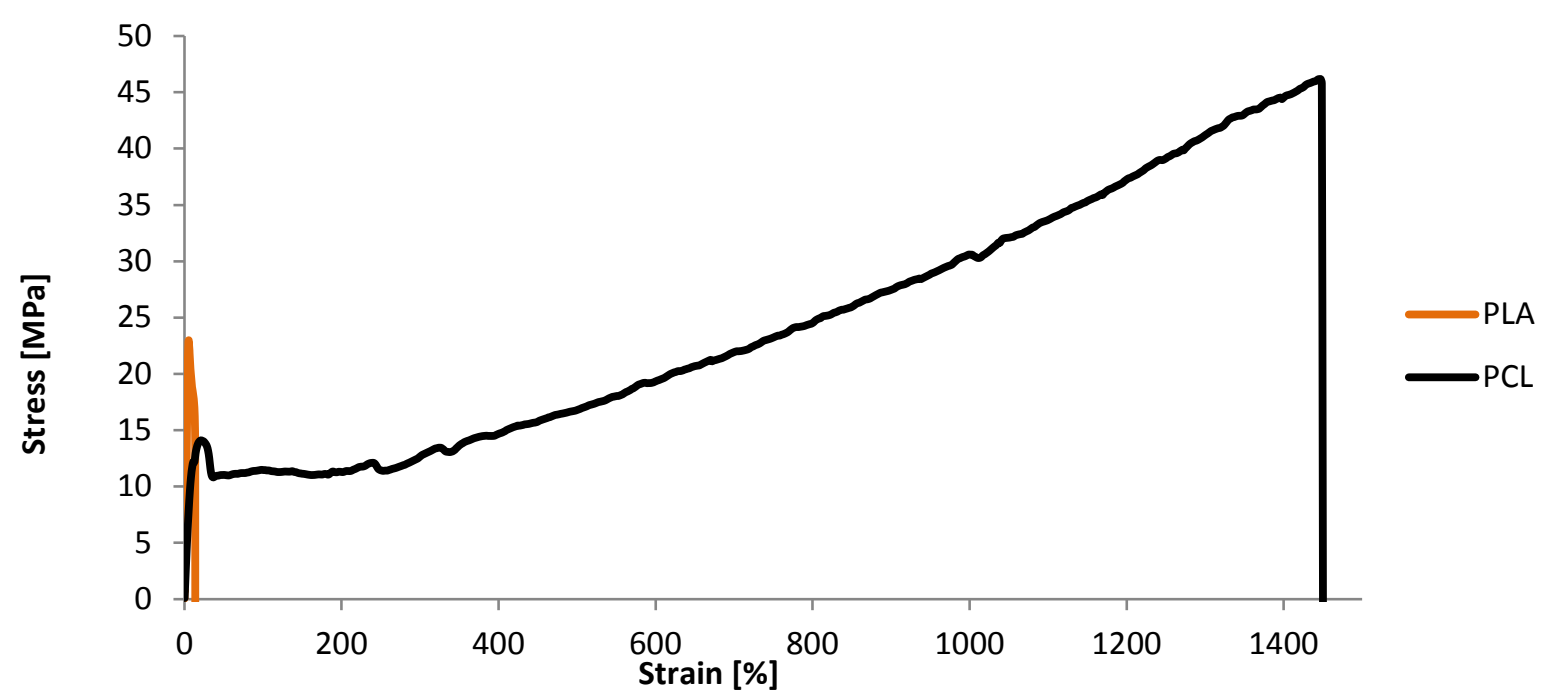

a)

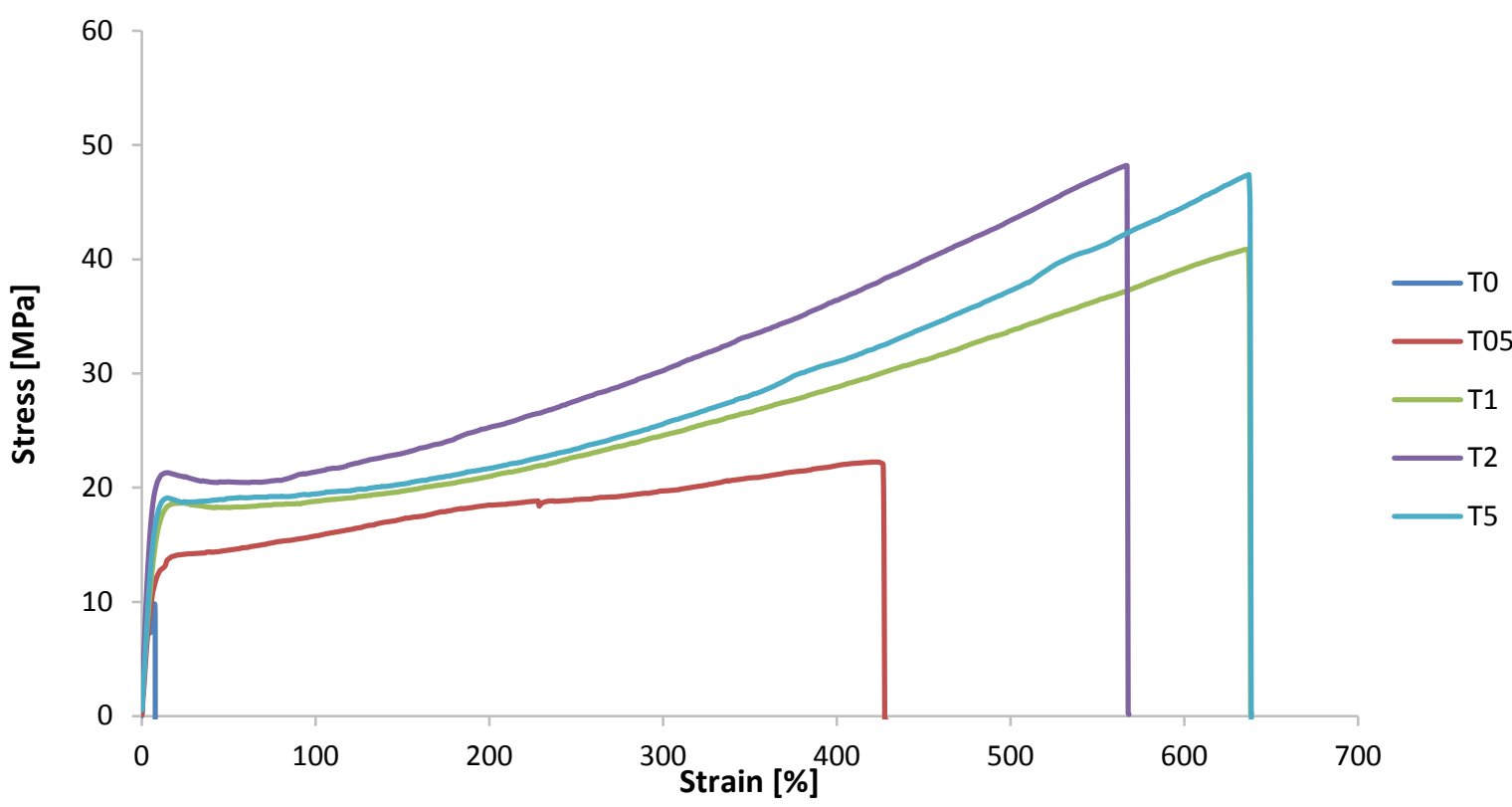

b)

Figure 3. Stress strain curves of a) PLA and PCL homopolymers, and b) all blends, obtained after physical or reactive mixing.

The stress-strain curves of PLA and PCL as homopolymers (Fig. 3a), obtained after the same mixing time, confirm the complementary behaviour of the two polyesters. The highest ductility of PCL is opposite to the stiffness and yield strength of PLA, as already discussed in literature $1 \mathrm{~b}, 1 \mathrm{c}, 1 \mathrm{~d}, 2,5,6$

When comparing the tensile tests results performed on all blends, (Figure 3b and Table 1) the T0 blend show a fragile behaviour similar to the pure PLA, while for all the other blends an increase in ductility is observed, irrespective of the LTI amount. Furthermore, an increase in mechanical 
strength is observed for increasing amounts of LTI. It is worth mentioning that the strain at yield, an index of the material resilience, has the highest value for the T05 blend (27\%, while T0 value is 3\%), while the stress at yield, an index of mechanical strength, reaches the highest value for the T5 blend, $20.2 \mathrm{MPa}$, an increase of $178 \%$ compared to the T0.

The increase in cross-linking density is affecting the elastic modulus, which becomes in the T5 blend almost double that of T05 (from 267 to $485 \mathrm{MPa},+82 \%$ ).

From a stoichiometric point of view, in the reactive blend T05 the addition of $0.5 \mathrm{~g}$ of LTI (molecular weight $=267.24 \mathrm{~g} / \mathrm{mol}$ ) in $100 \mathrm{~g}$ of blend corresponds to 0.002 moles (and 0.006 moles of available NCO reactive groups). A very rough estimate of the moles of chain ends present in our blend (based on the $M_{\mathrm{n}}$ values measured by GPC) gives a value of available $\mathrm{OH}$ in the order of 0.004 moles. In this respect, it is possible to speculate that at low loading of LTI, the reaction shown in Figure 2 is mainly forming branched copolymers with a random composition of PLA and PCL. When the loading is increased, the LTI tends to saturate all possible chain ends, thus forming a 3D, cross-linked network.

It should be considered that the mass between crosslinks is in all cases very high, as the LTI can only react with the chain end groups of both polymers, and this could be the reason for the high ductility observed even in the presence of $5 \mathrm{phr}$ of LTI. For that reason, the work at breakage of T5 has a value of $6.22 \mathrm{~J}$, while the value of T0 is only $0.02 \mathrm{~J}$ (an increase of more than 300 times), and the highest value of elongation at break is observed for the T1 blend, with $646 \%$ instead of 10\%. The work at breakage and the elastic modulus are plotted in Figure 4.

Table 2 - Mechanical properties of blends from tensile tests.

\begin{tabular}{|l|l|l|l|l|l|l|l|}
\hline Sample & $\begin{array}{l}\mathbf{E} \\
{[\mathbf{M P a}]}\end{array}$ & $\begin{array}{l}\mathbf{\varepsilon}_{\mathbf{y}} \\
{[\%]}\end{array}$ & $\begin{array}{l}\boldsymbol{\sigma}_{\mathbf{y}} \\
{[\mathbf{M P a}]}\end{array}$ & $\begin{array}{l}\boldsymbol{\sigma}_{\mathbf{m}} \\
{[\mathbf{M P a}]}\end{array}$ & $\begin{array}{l}\boldsymbol{\varepsilon} \mathbf{b} \\
{[\mathbf{\%}]}\end{array}$ & $\begin{array}{l}\boldsymbol{\sigma}_{\mathbf{b}} \\
{[\mathbf{M P a}]}\end{array}$ & $\begin{array}{l}\mathbf{W}_{\mathbf{b}} \\
{[\mathbf{J}]}\end{array}$ \\
\hline PLA & $816 \pm 120$ & $6 \pm 1$ & $22.4 \pm 1.6$ & $22.4 \pm 1.6$ & $15 \pm 4$ & $15.1 \pm 0.9$ & $0.08 \pm 0.03$ \\
\hline PCL & $154 \pm 26$ & $19 \pm 3.3$ & $14.0 \pm 0.9$ & $43.0 \pm 6.0$ & $1405 \pm 243$ & $39.8 \pm 4.8$ & $10.81 \pm 3.01$ \\
\hline T0 & $334 \pm 48$ & $3 \pm 0.7$ & $7.2 \pm 0.6$ & $10.0 \pm 0.9$ & $10 \pm 2$ & $9.5 \pm 0.6$ & $0.02 \pm 0.01$ \\
\hline T05 & $267 \pm 47$ & $27 \pm 8$ & $13.2 \pm 1.0$ & $21.8 \pm 2.8$ & $446 \pm 81$ & $21.5 \pm 2.8$ & $3.05 \pm 0.92$ \\
\hline T1 & $370 \pm 51$ & $21 \pm 5$ & $17.6 \pm 1.2$ & $39.0 \pm 2.1$ & $646 \pm 38$ & $38.8 \pm 2.1$ & $5.72 \pm 0.41$ \\
\hline T2 & $473 \pm 45$ & $14 \pm 2$ & $20.0 \pm 0.7$ & $43.4 \pm 6.0$ & $534 \pm 71$ & $43.0 \pm 6.4$ & $6.20 \pm 1.36$ \\
\hline T5 & $485 \pm 57$ & $16 \pm 1$ & $20.2 \pm 1.4$ & $45.7 \pm 1.9$ & $586 \pm 68$ & $45.6 \pm 2.0$ & $6.2 \pm 0.5$ \\
\hline
\end{tabular}



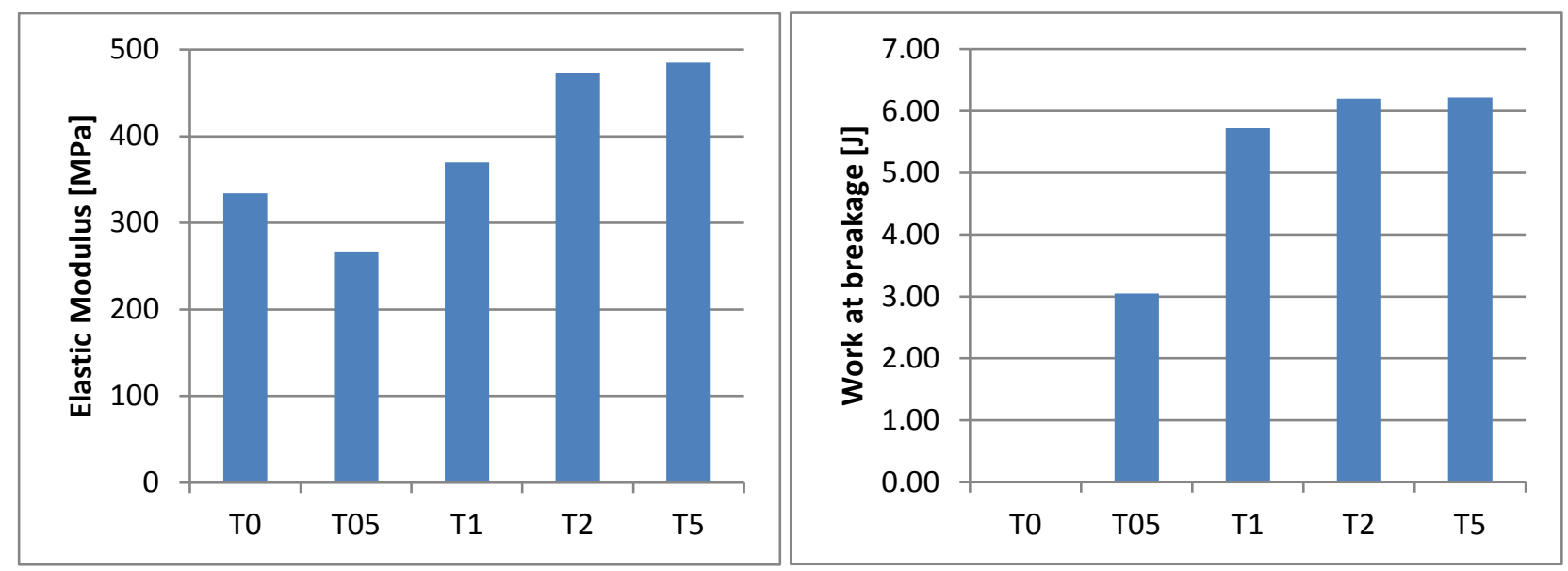

Figure 4.Elastic modulus and work at breakage as a function of the LTI amount in the blends.

The Elastic modulus of blends can be theoretically estimated using the Equivalent Box Model ${ }^{13}$. The model estimates the elastic modulus of a blend based on the relative elastic moduli of the components (E1, E2), their volume fractions $\left(\mathrm{v}_{1}, \mathrm{v}_{2}\right)$ and the parallel and serial parts of those fractions ( $\left.\mathrm{v}_{1 \mathrm{p}}, \mathrm{v}_{2 \mathrm{p}}, \mathrm{v}_{1 \mathrm{~s}}, \mathrm{v}_{2 \mathrm{~s}}\right)$, according to equation 5 :

$E_{b}=E_{1} v_{1 p}+E_{2} v_{2 p}+v_{s}^{2} /\left[\left(v_{1 s} / E_{1}\right)+\left(v_{2 s} / E_{2}\right)\right]$

In our blends, according to our previous study ${ }^{1 \mathrm{~b}}$, the experimental values of the elastic moduli for PLA and PCL are:

$E_{1}=E_{P L A}=815.91 \mathrm{MPa}$;

$E_{2}=E_{P C L}=153.70 \mathrm{MPa}$;

$v_{1 s}=0.31 ; v_{2 s}=0.31 ; v_{1 p}=0.19 ; v_{2 p}=0.19 ; v_{p}=v_{1 p}+v_{2 p} ; v_{s}=v_{1 s}+v_{2 s} ;$

The parallel or the serial fractions of the blends components have been evaluated theoretically following the method reported elsewhere ${ }^{13 \mathrm{f}}$.

The estimated value of $\mathrm{E}_{\mathrm{b}}, 344 \mathrm{MPa}$, is very close to the experimental result of the physical blend (334 MPa), confirming a good reliability of the model.

Instead, for all reactive blends (T05-T5), the experimental elastic moduli are not in line with the theoretical values (for example $473 \mathrm{MPa}$ in $\mathrm{T} 5$ blend), most probably due to the effect on mechanical properties of the new cross-linked phases in the system.

\subsection{Thermal characterization}

DSC traces for all blends and corresponding thermal parameters are given in Figure 5 and Table 3. The DSC traces clearly show a progressive decrease of melting and cold crystallization enthalpies 
with increasing amounts of LTI, a shift of the melting peak of PCL to lower temperatures and a shift of the cold crystallization peak of PLA to higher temperatures. These observations concur to reinforce the hypothesis that a progressively denser cross-linked network is formed, thus reducing the ability of the two polymers to crystallize.

Table 3 - Differential scanning calorimetry data for all blends.

\begin{tabular}{|c|c|c|c|c|c|c|c|c|c|c|}
\hline Sample & $\begin{array}{l}T_{\mathrm{m}} \\
\text { PCL } \\
\left({ }^{\circ} \mathrm{C}\right)\end{array}$ & $\begin{array}{l}\Delta H_{\mathrm{m}} \\
\text { PCL } \\
\text { (J) }\end{array}$ & $\begin{array}{l}T_{\mathrm{cc}} \\
\text { PLA } \\
\left({ }^{\circ} \mathbf{C}\right)\end{array}$ & $\begin{array}{l}\Delta H_{\mathrm{cc}} \\
\text { PLA } \\
(\mathrm{J})\end{array}$ & \multicolumn{2}{|l|}{$\begin{array}{l}T_{\mathrm{m}} \\
\text { PLA } \\
\left({ }^{\circ} \mathrm{C}\right)\end{array}$} & $\begin{array}{l}\Delta H_{\mathrm{m}} \\
\text { PLA } \\
(\mathrm{J})\end{array}$ & $\begin{array}{l}\chi_{i} \\
\text { PLA } \\
(\%)\end{array}$ & $\begin{array}{l}\chi_{\mathrm{cc}} \\
\text { PLA } \\
(\%)\end{array}$ & $\begin{array}{l}\chi \\
\text { PCL } \\
(\%)\end{array}$ \\
\hline T0 & 64.02 & 39.68 & 103.61 & 7.24 & 146.65 & 155.74 & 9.45 & 3.28 & 10.72 & 55.69 \\
\hline T05 & 62.83 & 35.57 & 111.05 & 6.21 & 148.31 & 154.37 & 8.35 & 3.17 & 9.20 & 49.92 \\
\hline $\mathrm{T} 1$ & 62.08 & 32.43 & 113.05 & 7.11 & 148.88 & 157.14 & 8.33 & 1.81 & 10.53 & 45.52 \\
\hline $\mathrm{T} 2$ & 61.87 & 32.32 & 113.50 & 3.86 & \multicolumn{2}{|l|}{149.46} & 6.80 & 4.36 & 5.72 & 45.36 \\
\hline T5 & 62.75 & 31.78 & 117.85 & 5.21 & \multicolumn{2}{|l|}{149.57} & 6.44 & 1.83 & 7.72 & 44.60 \\
\hline
\end{tabular}

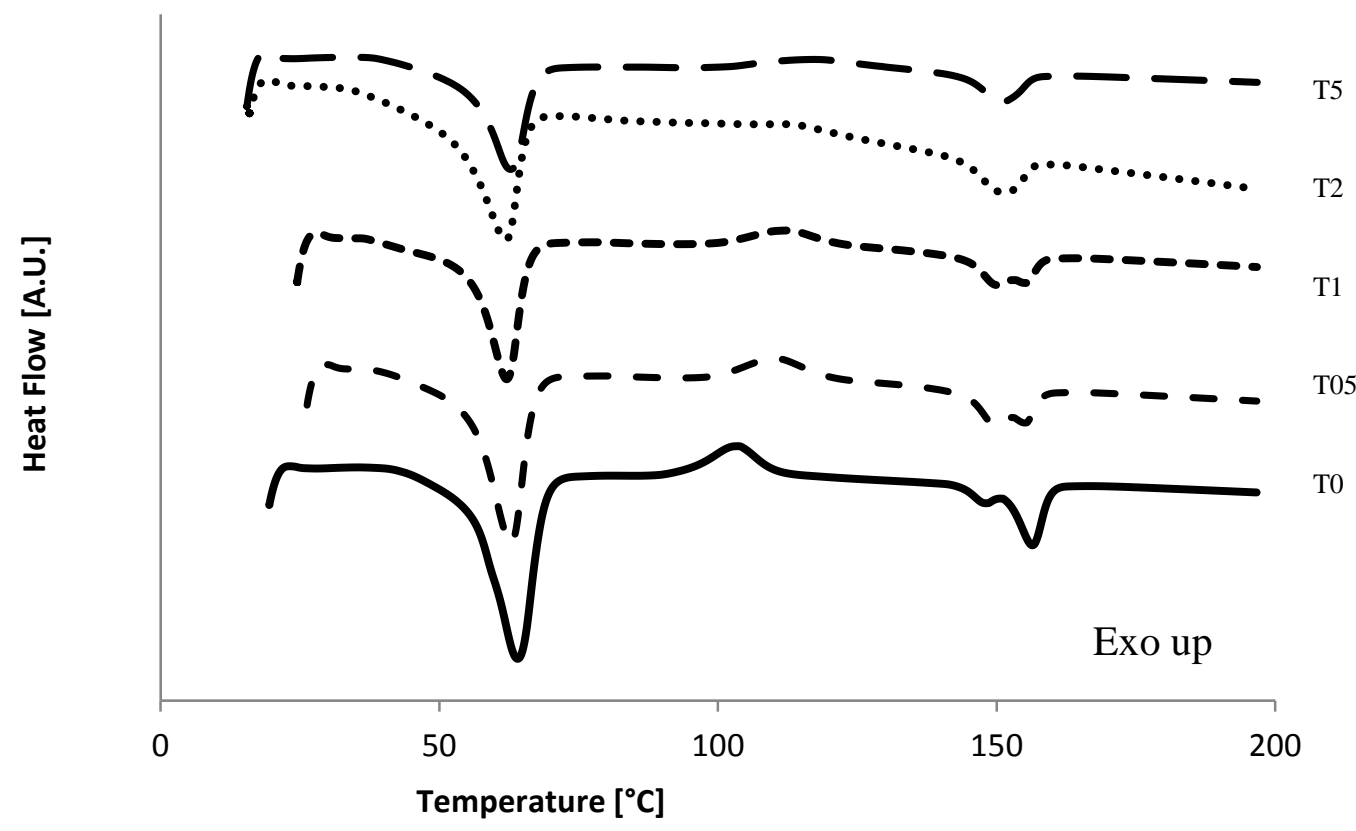

Figure 5. DSC thermograms for all blends.

\subsection{Rheology}


In Figure 6 are reported the shear amplitude sweeps of two blends, T0 and T1, with black squares indicating the storage modulus, red for the loss modulus and blue for the $\tan \delta$.

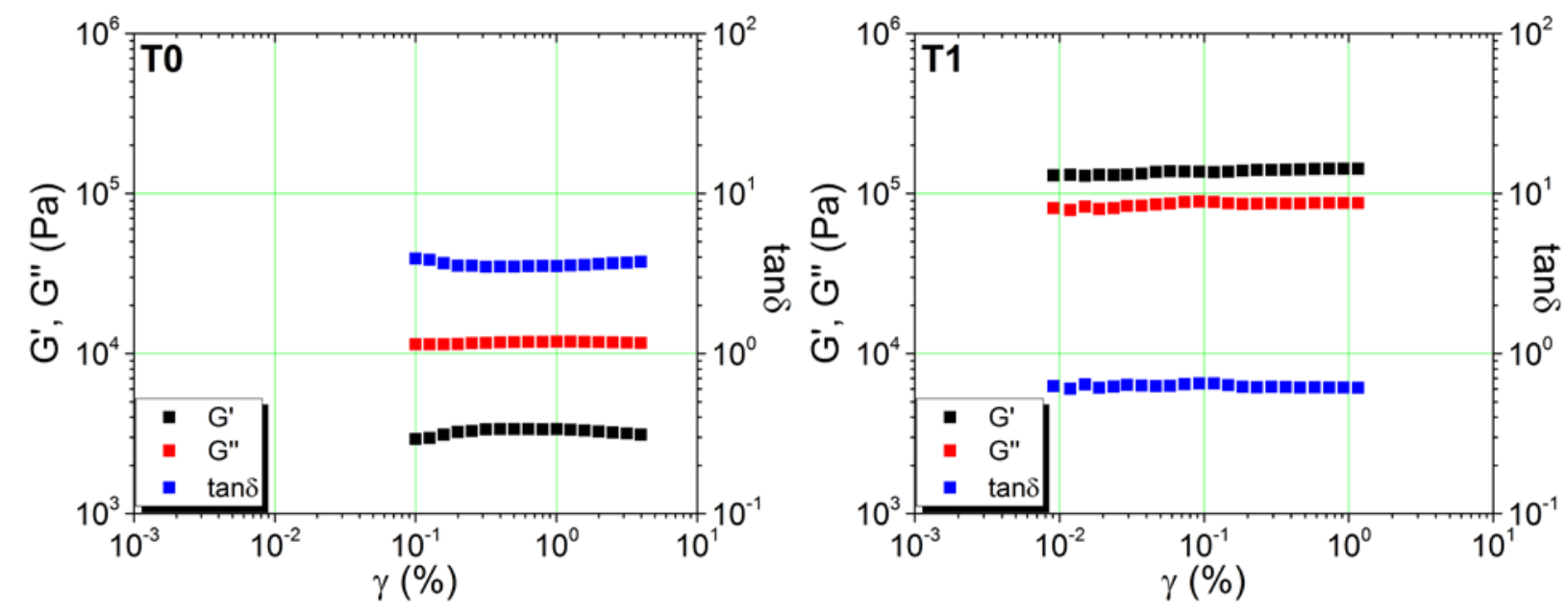

Figure 6. Shear amplitude response of physical blend $\mathrm{T} 0$ and reactive blend $\mathrm{T} 1$.

The linear viscoelastic regime, defined as the zone of linear response of the moduli in a strain modulation experiment, has been estimated to be up to $0.8 \%$ of strain and this value has been used for the subsequent experiments. As Figure 6 shows, just 1 phr of LTI is enough to observe an increase of the storage modulus of several order of magnitude. In figure 7 are reported the storage moduli as a function of time for the various blends when a constant temperature of $150{ }^{\circ} \mathrm{C}$ and a 0.8 $\%$ of strain are applied. 


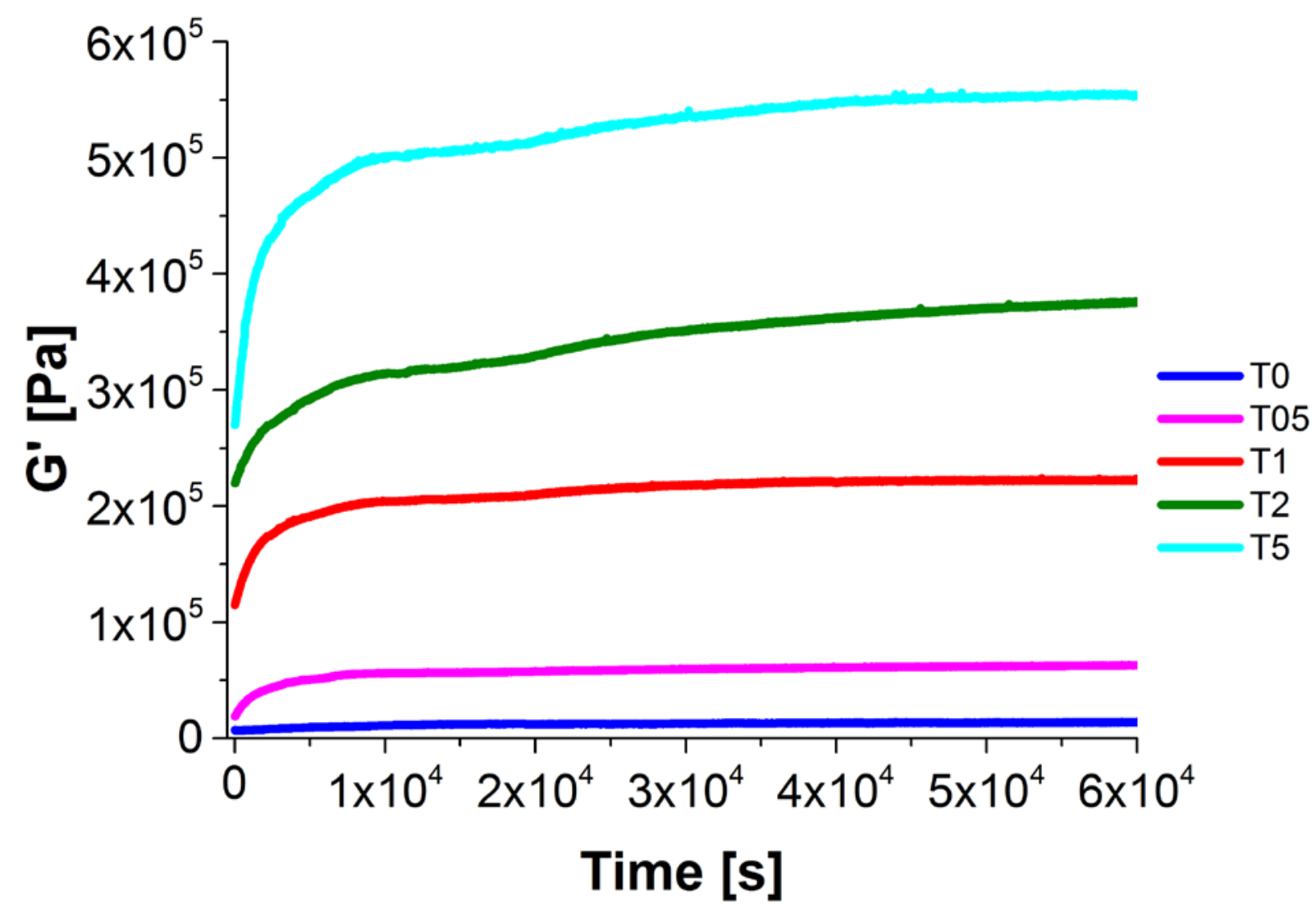

Figure 7. Time evolution of storage modulus G' for all blends. The modulus remains constant for the T0 blend, while a progressive increase is observed for all reactive blends.

It is interesting to observe that the storage modulus for the T0 blend does not change with time, while an increase is observed for all the reactive blends, and it is more pronounced, the higher the amount of LTI is. This result can be explained if we postulate that the reaction between LTI and the available $\mathrm{OH}$ groups is not completed during the thermo-mechanical processing, and the different plateau values correspond to fully-cured materials with increasing cross-linking density. As the amount of LTI in the blends increases, both the slope of the build-up curves and the G' values increase, suggesting that the reaction kinetics and the obtained cross-linking density are governed by the reactive agent amount. Therefore, from a proper viscous thermoplastic melt, with the progressive increase of the carbamates links, we produced a series of materials with an evident elastic and/or rubber-like behaviour.

Once all the blends reached a plateau value, indicating that an equilibrium situation had been achieved, frequency sweep experiments were conducted. The frequency response experiments data are plotted in Figure 8, showing the trends for both storage (G') and loss (G”) moduli. In both cases, moduli values increase with increasing the LTI content. These results are in line with the previous 
characterizations, and confirm the formation of a cross-linked network showing a solid-like behaviour.
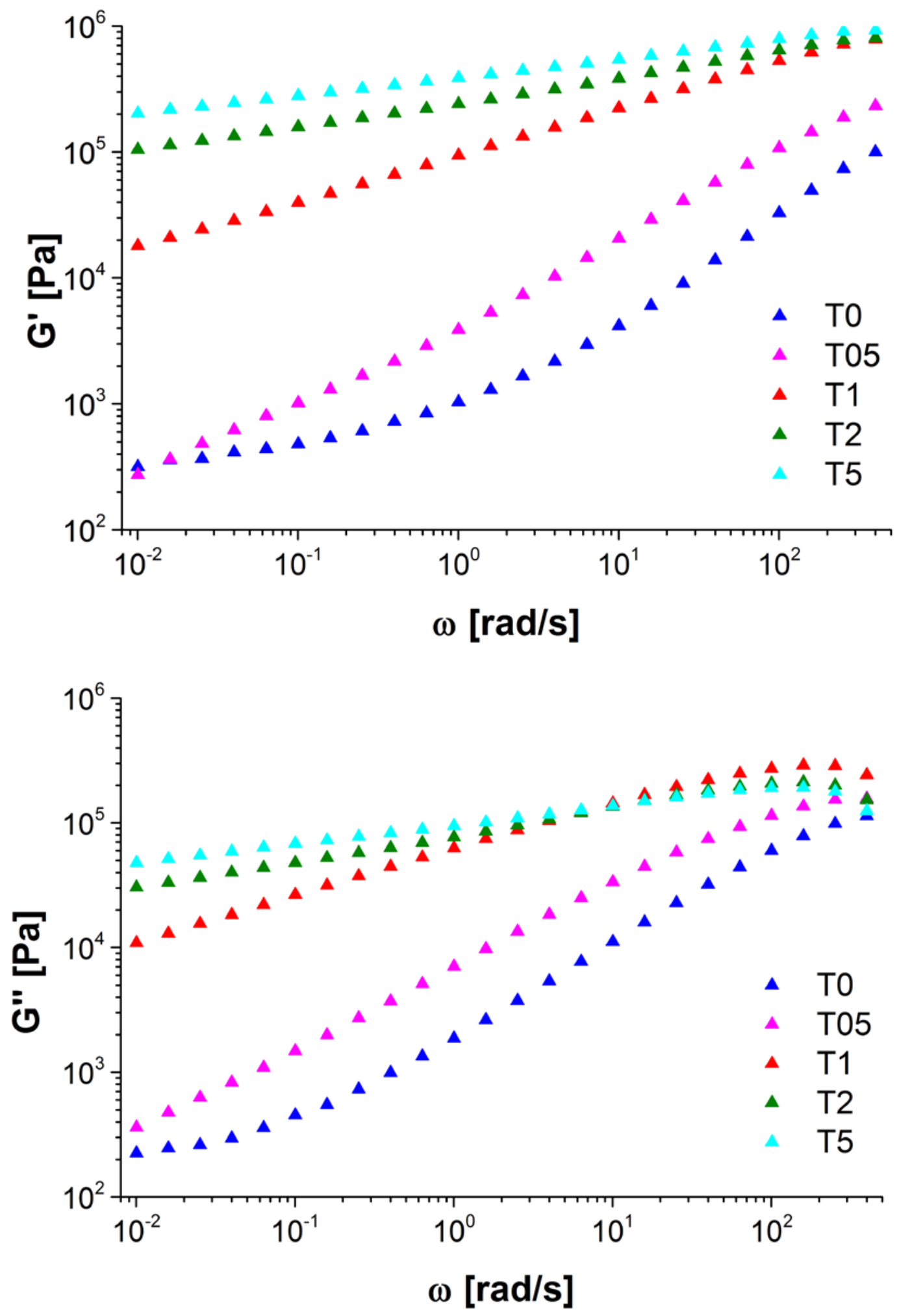

Figure 8. Frequency response of physical and reactive blends; top: G', bottom: G”. 
The storage modulus trend of the T0 blend shows an evident change in slope at frequencies below 1 $\mathrm{rad} / \mathrm{s}$. This variation of the elastic behavior, according to previous studies, is attributed to the shape relaxation of the dispersed phase, often observed in the shape of big circular droplets, due the high interfacial energy exhibited by PLA and PCL when mixed.

In the low frequencies region, the effect of this interfacial interaction is more prominent ${ }^{4 a}$. The disappearance of this slope change in all reactive blends suggests a much finer dispersion of the two phases, and a lower interfacial energy.

For the reactive blends containing 1phr or more of LTI, the values of G' are higher than G” in the entire range of frequencies examined. This suggests a transition from a proper molten thermoplastic behaviour displayed by T0 and T05, to a solid, rubber-like behaviour, typical of a cross-linked structure, displayed by the remaining reactive blends. It is also evident how the gap between the two moduli becomes wider as the LTI content increases, indicating a denser cross-linking.

Rheological characterisations confirm what observed already from the tensile tests, where the T05 reactive blend seems to be the boundary between a binary system compatibilized by the in-situ formation of copolymers and a crosslinked network.

\subsection{Numerical Modeling of Rheological Properties}

The Cole-Cole or four-parameter fractional derivative Zener function model was applied to describe the experimental data obtained from rheology.

The complex, real and imaginary parts of modulus follow the Equations 6 to 8 respectively, as follows:

$$
\begin{aligned}
& G^{*}=G_{o}+\frac{\left(G_{\infty}-G_{o}\right)(i \omega \tau)^{\beta}}{1+(i \omega \tau)^{\beta}}=G^{\prime}+i G^{\prime \prime} \\
& G^{\prime}=G_{o}+\frac{\left(G_{\infty}-G_{o}\right)\left[\left(\frac{\omega}{\omega_{\max }}\right)^{\beta} \cos \left(\frac{\beta \pi}{2}\right)+\left(\frac{\omega}{\omega_{\max }}\right)^{2 \beta}\right]}{1+2\left(\frac{\omega}{\omega_{\max }}\right)^{\beta} \cos \left(\frac{\beta \pi}{2}\right)+\left(\frac{\omega}{\omega_{\max }}\right)^{2 \beta}} \\
& G^{\prime \prime}=\frac{\left(G_{\infty}-G_{o}\right)\left(\frac{\omega}{\omega_{\max }}\right)^{\beta} \sin \left(\frac{\beta \pi}{2}\right)}{1+2\left(\frac{\omega}{\omega_{\max }}\right)^{\beta} \cos \left(\frac{\beta \pi}{2}\right)+\left(\frac{\omega}{\omega_{\max }}\right)^{2 \beta}}
\end{aligned}
$$

where $\lim _{\omega \rightarrow \infty} G=G_{\infty}$ is the high-frequency limit value of the dynamic modulus, $\lim _{\omega \rightarrow 0} G=G_{0}$ is the zero frequency limit value of the dynamic modulus, $\omega_{\max }$ is the frequency loss peak position and $\beta$ is the model's parameter where $0<\beta<1$. For $\beta=1$, the conventional Zener model applies implying the existence of a single relaxation time $e^{9,10}$, while $\beta$ approaching 0 indicates a wide distribution of relaxation times. 
When more relaxation processes take place, the superposition of the individual relaxations needs to fit the experimental data, according to Equations 9-10: ${ }^{14}$

$G_{S}^{\prime}=\sum_{1}^{N} G_{N}^{\prime}$

$G_{S}^{\prime \prime}=\sum_{1}^{N} G_{N}^{\prime \prime}$

where $G_{S}^{\prime}$ and $G_{S}^{\prime \prime}$ are the real and imaginary parts of the modulus superposition for $N$ processes.

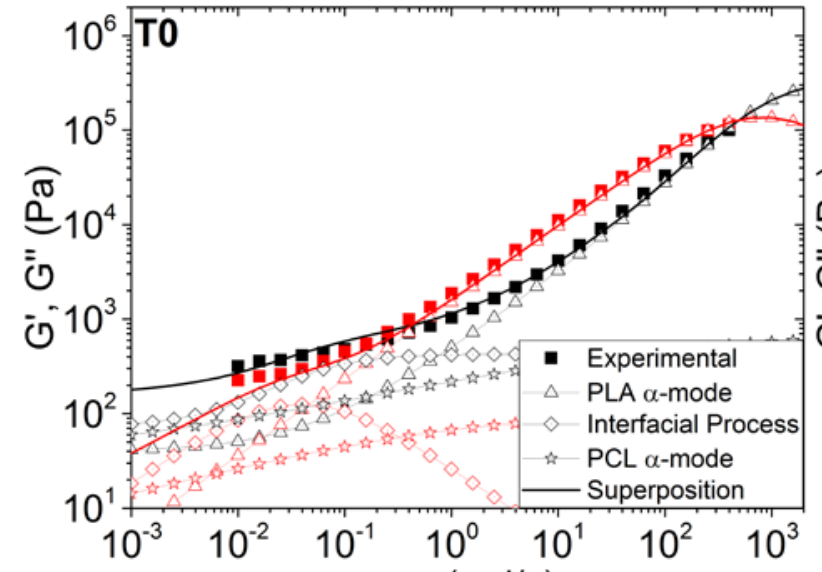

$\omega(\mathrm{rad} / \mathrm{s})$
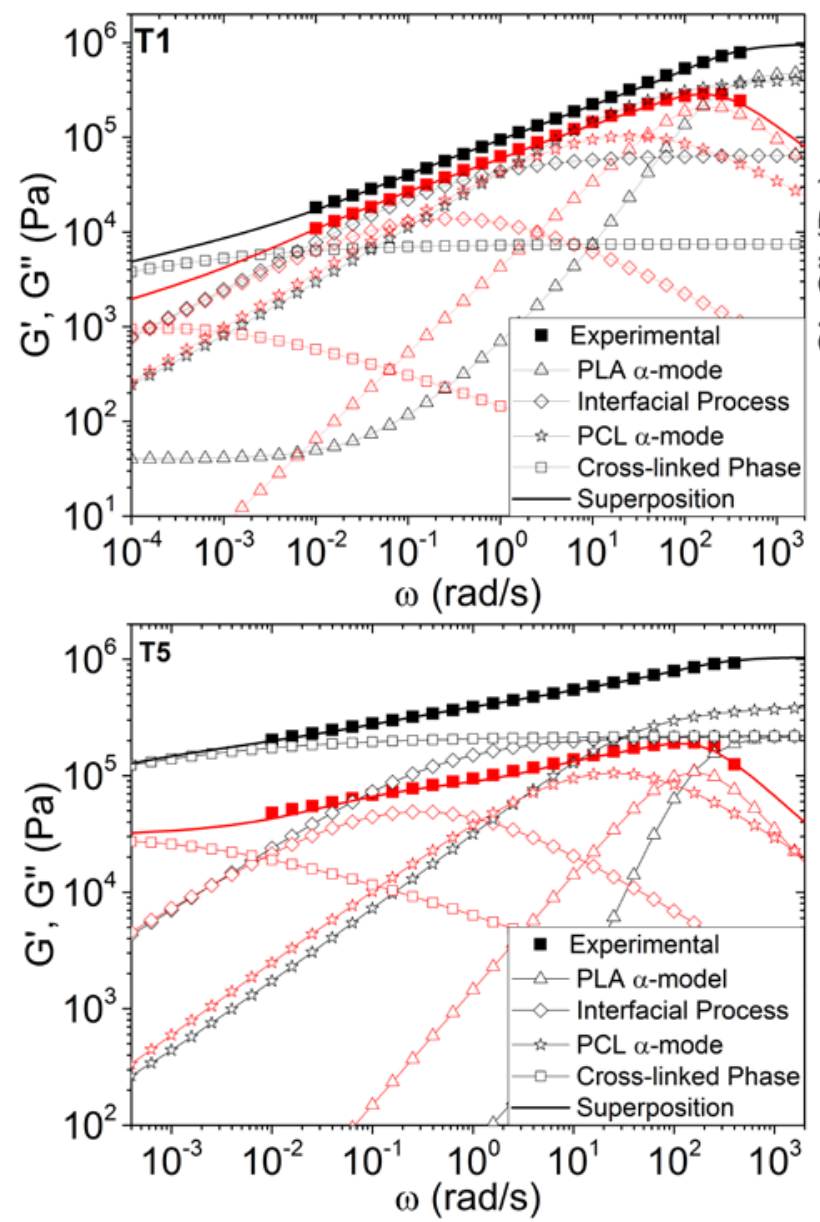

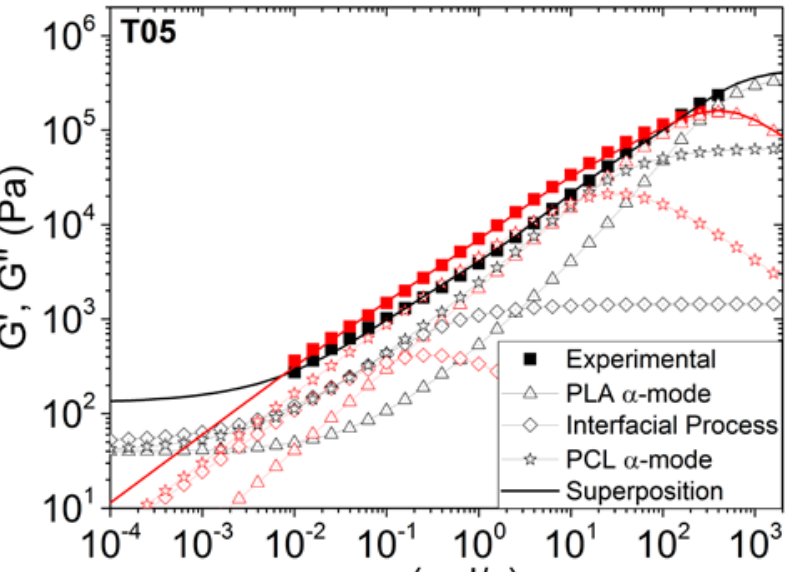

$\omega(\mathrm{rad} / \mathrm{s})$

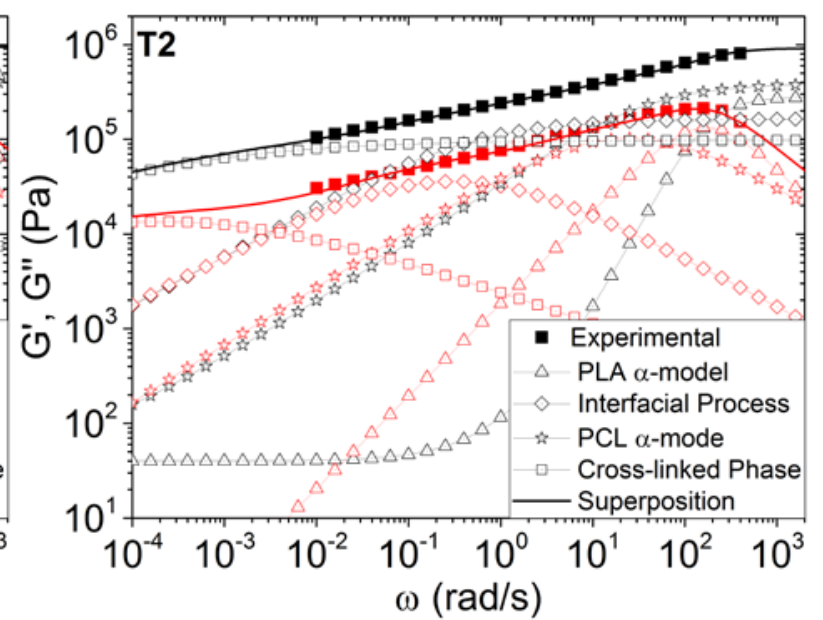

Figure 9. The storage and loss moduli, corresponding to real and imaginary part of the complex modulus, as a function of angular frequency at $150{ }^{\circ} \mathrm{C}$ for all blends, with corresponding fitting 
according to the Cole-Cole or four-parameter fractional derivative Zener function model. Black represents the real part while red the imaginary part of the complex modulus.

Figure 9 presents the storage and loss modulus as a function of angular frequency at $150^{\circ} \mathrm{C}$ for all studied specimens. The rheological behaviour was fitted following the model described above, where the $\alpha$-modes of PLA and PCL and the interfacial process between them where described. The solid squares represent the experimental values as obtained from rheology, while the solid lines represent the superposition of the individual relaxations (shown as open symbols).Two phases were sufficient to perfectly fit the behavior of the T0 and T05 blends. From the T1 blend onwards, a third phase had to be introduced in order to fit the experimental data. According to the model's parameters presented in Table 4, the $\beta$ parameter of PCL's and PLA's $\alpha$-modes is generally increasing with the addition of LTI, approaching a more ideal rheological behaviour with a single relaxation time. This provides evidence that the distribution within the chains of each polymer type is diminishing, and it can be attributed to the growing cross-linked phase. The contribution of the cross-linked phase, as expected, increases with the addition of LTI (the $G_{\infty}$ factor increases) as it gains more mass, while the distribution of relaxation modes is almost unperturbed between 1 and 5 phr LTI $(\beta \approx 0.3$ ). Additional information that can be retrieved from the numerical modelling are the shift of PLA loss peak to lower frequencies, the reduction of $G_{\infty}$ and the increase of both the $\alpha$ mode of PCL and the interfacial process with increasing LTI amounts. All these observations concur to strengthen the hypothesis that LTI reacting with chain ends of both PCL and PLA, initially creates an in-situ copolymer that improves the polymers blending for T05, while for LTI of 1 phr and above, a third phase appears from the extensive crosslinking. The boundary between the T05 and the T1 represents the switch from a 2-phase interface to a 3-phase interface, evident in the sudden jump of $G_{\infty}$ from 1.45 to 65 and the corresponding decrease of $\beta$, that can be attributed to broader distribution and complexity of relaxation modes between the 3 phases. 
Table 4 - Parameters used for the Cole-Cole function model where $G_{0}$ and $G_{\infty}$ are the values of modulus in zero and infinite frequency respectively, $\omega_{\max }$ is the loss peak position and $\beta$ is the model's parameter.

\begin{tabular}{|c|c|c|c|c|c|}
\hline Blend & Process & $G_{0}(\mathrm{kPa})$ & $G_{\infty}(\mathbf{k P a})$ & $\omega_{\max }(\mathrm{rad} / \mathrm{s})$ & $\beta$ \\
\hline \multirow{3}{*}{ T0 } & $\alpha$-mode PLA & 0.040 & 370 & 825 & 0.812 \\
\hline & $\alpha$-mode PCL & 0.030 & 0.75 & 27 & 0.298 \\
\hline & InterfacialProcess & 0.070 & 0.43 & 0.04 & 0.779 \\
\hline \multirow{4}{*}{ T05 } & $\alpha$-mode PLA & 0.040 & 385 & 420 & 0.857 \\
\hline & $\alpha$-mode PCL & 0.040 & 65 & 30 & 0.736 \\
\hline & InterfacialProcess & 0.050 & 1.45 & 0.30 & 0.685 \\
\hline & Cross-Linked & - & - & - & - \\
\hline \multirow{4}{*}{ T1 } & $\alpha$-mode PLA & 0.040 & 495 & 185 & 0.908 \\
\hline & $\alpha$-mode PCL & 0.040 & 425 & 25 & 0.576 \\
\hline & InterfacialProcess & 0.050 & 65 & 0.30 & 0.513 \\
\hline & Cross-Linked & 1.000 & 7.50 & 0.0002 & 0.367 \\
\hline \multirow{4}{*}{$\mathbf{T} 2$} & $\alpha$-mode PLA & 0.040 & 280 & 170 & 0.978 \\
\hline & $\alpha$-mode PCL & 0.040 & 395 & 25 & 0.609 \\
\hline & InterfacialProcess & 0.050 & 165 & 0.30 & 0.523 \\
\hline & Cross-Linked & 1.000 & 98 & 0.0002 & 0.347 \\
\hline \multirow{4}{*}{ T5 } & $\alpha$-mode PLA & 0.040 & 220 & 160 & 0.989 \\
\hline & $\alpha$-mode PCL & 0.040 & 395 & 25 & 0.623 \\
\hline & InterfacialProcess & 0.050 & 220 & 0.30 & 0.535 \\
\hline & Cross-Linked & 1.000 & 220 & 0.0002 & 0.315 \\
\hline
\end{tabular}

The Cole-Cole curve $\left(G^{\prime \prime}=f\left(G^{\prime}\right)\right)$ at $150^{\circ} \mathrm{C}$ for all studied specimens is presented in Figure 10. The symbols represent the experimental data, while the lines are the superposition of the modelled relaxation processes of each specimen. While the curves for T0 and T05 originates from $(0,0)$, confirming that we experimentally observe the full relaxation modes of the two-phase components, the curves for $\mathrm{T} 1$ and higher are progressively shifted, supporting the existence of a third component with very high relaxation times. 


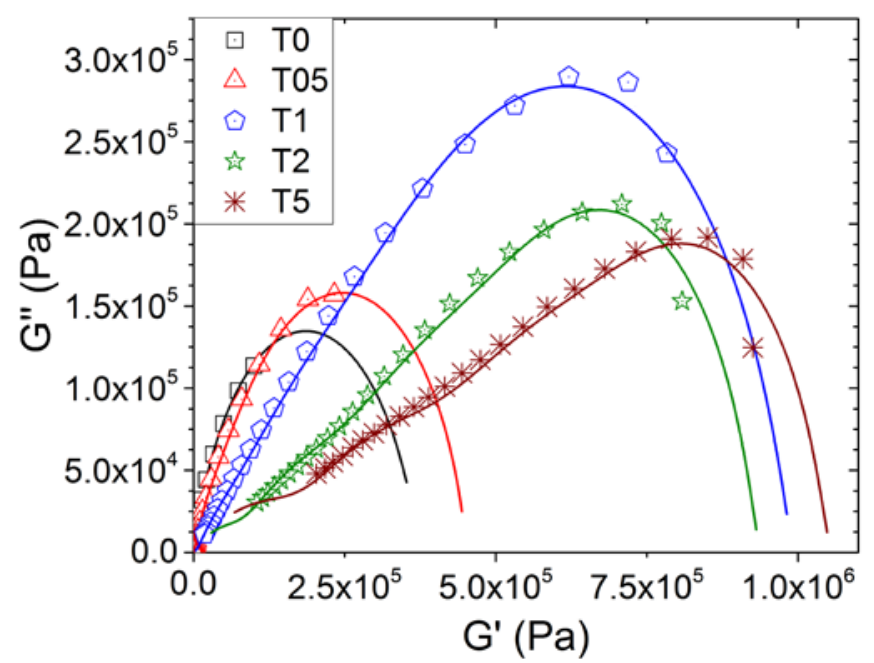

Figure 10.Cole-Cole plot of all the specimens at $150^{\circ} \mathrm{C}$.

\subsection{SEM characterization}

SEM images have been acquired following the thermo-mechanical blending, before and after rheological experiments. The images shown in Fig. 11 correspond to samples before the fullcuring/build-up process in the rheometer. The LTI effect on the morphology of the blends is evident and clearly dependent on the amount. The physical blend shows an heterogeneous morphology, with wide PLA spherical droplets that, according to previous studies ${ }^{6 \mathrm{~b}, 6 \mathrm{c}}$, is due to the interfacial tension between the polyesters solidifying from molten state. The reactive blends show a much finer dispersion, with smaller droplets, as noticeable by the T2-T5 images (Fig. 11).

From T1 to T5 images, it is possible to have visual evidence of a third phase, indicated by the arrows in Fig. 11, which seems to be in acicular shapes. The acicular shape could be originating from the shear induced during the mixing of blends.The formation of these particles could justify the effect detected on the mechanical properties, similarly to what happens when rod-like particulate is added to blends. Previous studies have found that mechanical properties, like elastic

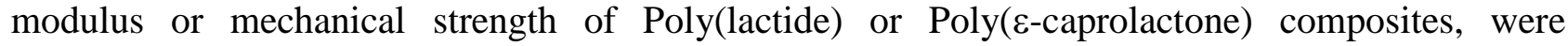
improved by addition of particles like $\mathrm{SiO}_{2}$ or carbon ${ }^{15}$.

The T5 blend presents an overall rougher morphology, probably because the third phase is extensively present as an amorphous and brittler component in the blends. 

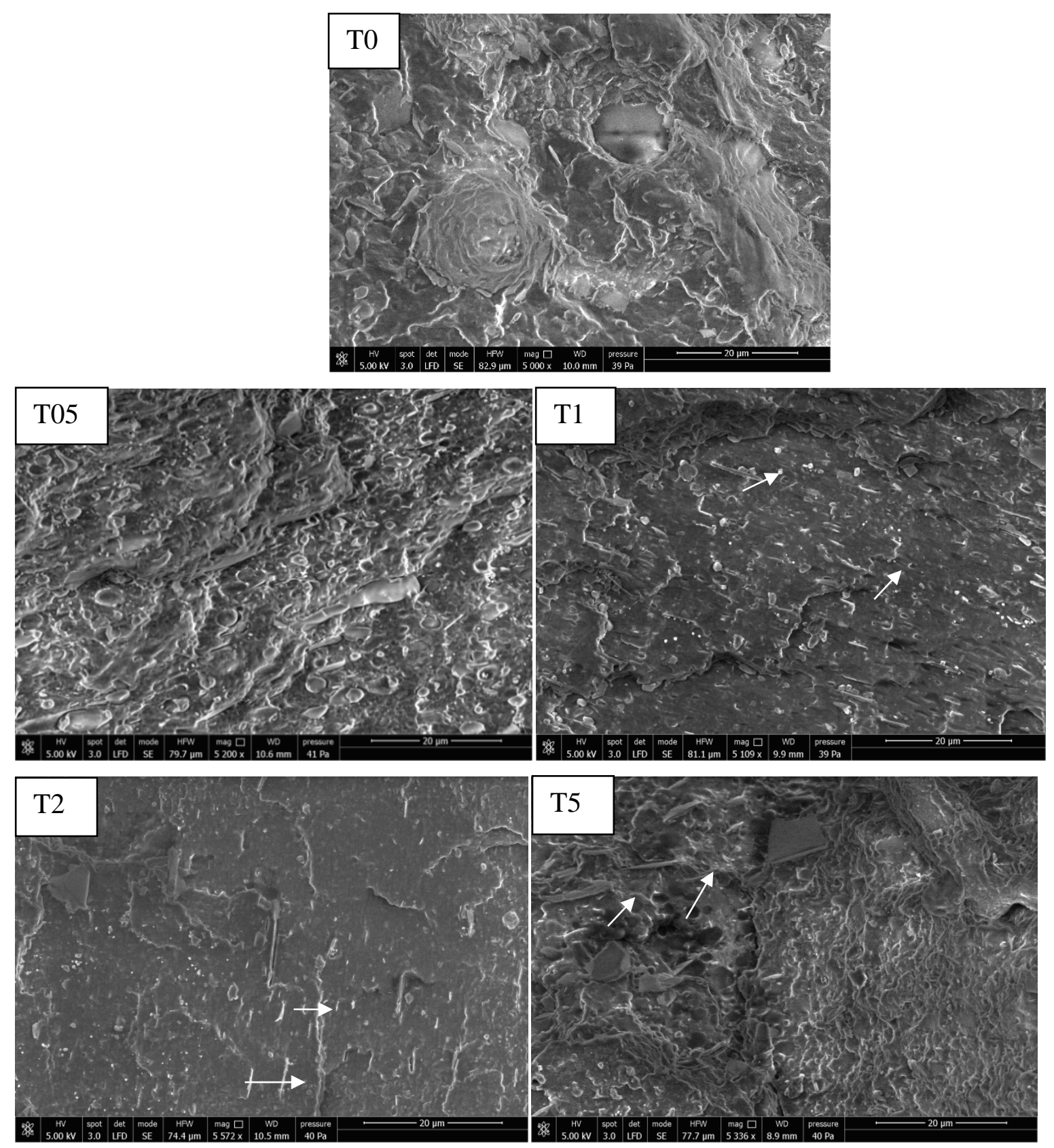

Figure 11. SEM images of physical and reactive blends before rheology. 

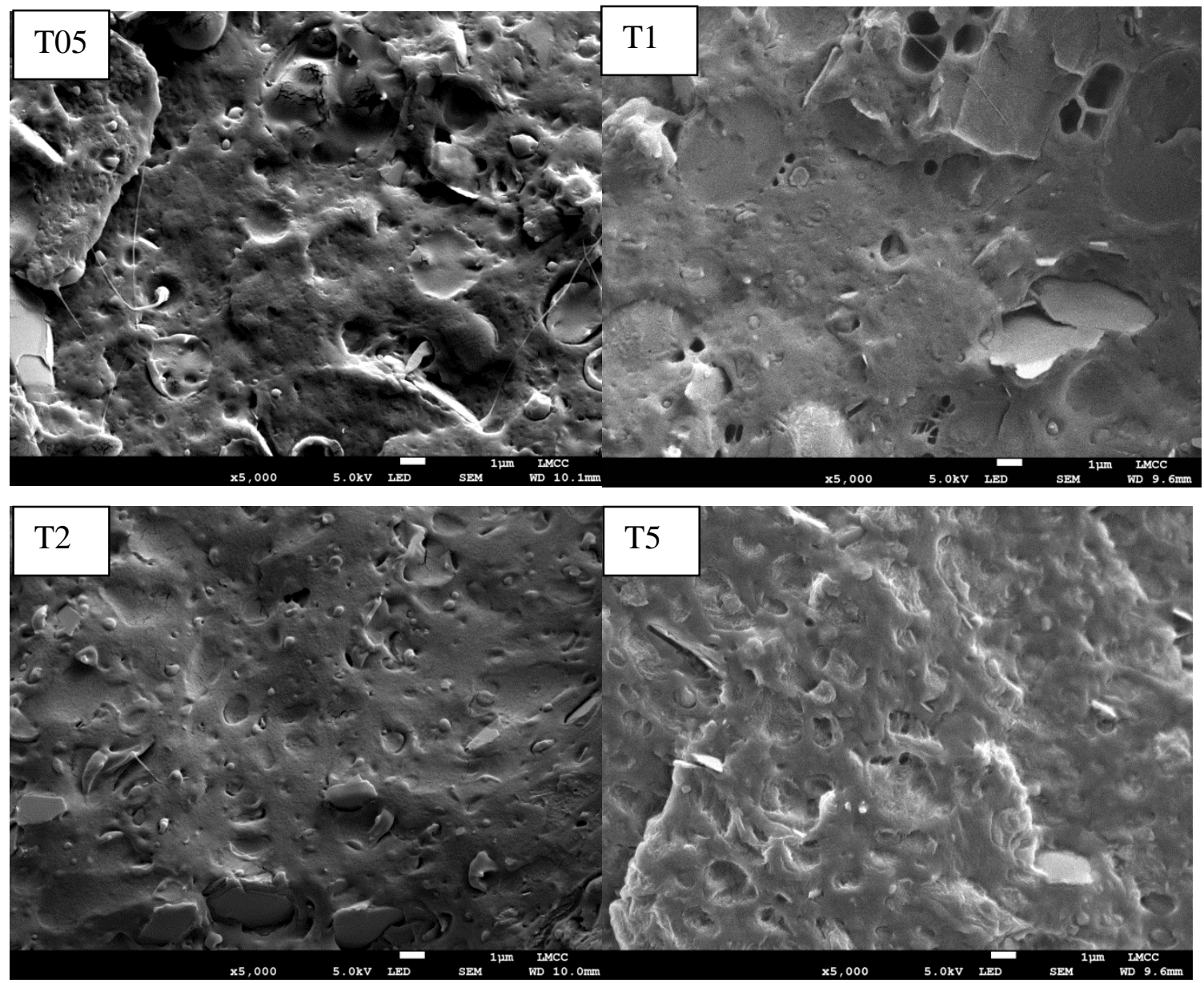

Figure 12. SEM images of reactive blends after $8 \times 10^{4} \mathrm{~s}$ at $150{ }^{\circ} \mathrm{C}$.

As shown in Figure 12, after the 'curing' observed in the rheometer, reactive blends exhibit a smoother and more homogeneous surface, despite what observed previously in particular for the T5 blend. That is probably due to the increased size of the network, in which some particles of unreacted polymers are finely dispersed, following the high temperature shear in the rheometer.

No degradation processes seem to occur, suggesting that the LTI presence in the blends could slow down these phenomena, with a mechanism which is still under study.

\section{Conclusions}

The addition of a reactive agent, LTI, to 50/50 wt \% mixtures of PLA and PCL can improve dramatically the mechanical performance of the resulting blends. The effect on the blends of increasing amounts of LTI from 0.5 up to 5 phr has been followed by thermal, mechanical and optical characterizations, including torque, tensile tests, rheology, DSC and SEM. 
Experimental data from all techniques concur to suggest that at low levels of LTI (0.5 phr, T05) the resulting blend is displaying a thermoplastic behavior and a finer dispersion, while for LTI $\geq 1 \mathrm{phr}$ a third phase with a rubber-like behavior appear to be forming. Our hypothesis to justify the observed response is that at lower level of LTI, the random reaction with PLA and PCL chain ends results in the in-situ formation of three-armed copolymers that improve the polymers compatibility. For LTI amounts $\geq 1 \mathrm{phr}$, a progressive saturation of the chain end groups leads to the formation of a crosslinked network constituting by all means a third phase.

Mechanical characterization showed how the ductility was maintained for all blends, also when the LTI amount is as high as 5phr, thanks to long spacing between the cross-links. Elastic modulus and mechanical strength of all materials appeared to be improved for the reactive blends compared to the pure blend $\mathrm{T} 0$.

The appearance of a third phase from blends containing $\geq 1$ phr of LTI was further supported by the numerical modelling of the rheological results via the Cole-Cole or four-parameter fractional derivative Zener function model.

\section{Acknowledgments}

The authors wish to thank Keith Yendall for SEM characterization on JEOL 7800F Field Emission Scanning Electron Microscope, and the Unime Research and Mobility 2016 project for founds on research activities.

\section{References}

1] a) R. Dell’Erba, G. Groeninckx, G. Maglio, M. Malinconico, A. Migliozzi. 2001, Immiscible polymer blends of semicrystalline biocompatible components: thermal properties and phase morphology analysis of PLLA/PCL blends. Polymer, 42, 7831-7840; b) A.Visco, D.Nocita, A.Giamporcaro, S. Ronca, G. Forte, A. Pistone, C. Espro, 2017. Effect of Ethyl Ester L-Lysine Triisocyanate addition to produce reactive PLA/PCL bio-polyester blends for biomedical applications. Journal of the Mechanical Behavior of Biomedical Materials, 68, 308-317; c) D. Wu, Y. Zhang, M. Zhang, W. Yu, 2009.Selective Localization of Multiwalled Carbon Nanotubes inPoly(E-caprolactone)/Polylactide Blend.Biomacromolecules, 10, 417-424; d) M. Harada, K. Iida, K. Okamoto, H. Hayashi, K. Hirano, 2008. Reactive compatibilization of biodegradable poly(lactic acid)/poly(e-caprolactone)blends with reactive processing agents. Polymer Engineering And Science, 1359-1368; e) M. Harada, T. Ohya, K. Iida, H. Hayashi, K. Hirano, H. Fukuda, 2007. Increased impact strength of biodegradable poly(lactic acid)/poly(butylene-succinate) blend 
composites by using isocyanate as a reactive processing agent. Journal of Applied Polymer Science, 1813-1820.

2] J. Urquijo, G. Guerrica-Echevarrìa, J.I. Eguiazàbal, 2015. Melt processed PLA/PCL blends:

effect of processing method on phase structure, morphology, and mechanical properties. Journal Of Applied Polymer Science, 132, 42641 (1-9).

3]S.A. Guelcher, A. Srinivasan, J.E. Dumas, J.E. Didier, S. McBride, J.O. Hollinger,2008.Synthesis, mechanical properties, biocompatibility, and biodegradation of polyurethane networks from lysine polyisocyanates. Biomaterials, 29 , 1762-1775.

4] a) H. Tsuji, T. Yamada, M. Suzuki, S. Itsuno, 2003. Blends of aliphatic polyesters.Part 7. Effects of poly(L-lactide-co- $\varepsilon$-caprolactone) on morphology, structure, crystallization, and physical properties of blends of poly(L-lactide) and poly( $\varepsilon$-caprolactone). Polymer International, 52, 269275; b) M. Rizzuto, A. Mugica, M. Zubitur, D. Caretti, A. J. Müller, 2016. Plasticization and antiplasticization effects caused by poly(lactide-ran-caprolactone) addition to double crystalline poly(llactide)/poly(E-caprolactone)blends. Cryst Eng Comm, 18,2014-2023; c) C. Zhang, T. Zhai, L. Turng, Y. Dan, 2015. Morphological, Mechanical, and Crystallization Behavior of Polylactide/Polycaprolactone Blends Compatibilized by l-Lactide/Caprolactone Copolymer. Industrial \& Engineering Chemistry Research, 54, 9505-9511; d) T.Semba, K. Kitagawa, U. S Ishiaku, H. Hamada, 2006. The effect of crosslinking on the mechanical properties of polylactic acid/polycaprolactone blends. Journal Of Applied Polymer Science, 101, 1861- 1825; e) T. Takayama, M. Todo, H. Tsuji, 2011. Effect of annealing on the mechanical properties of PLA/PCL and PLA/PCL/LTI polymer blends. Journal Of The Mechanical Behavior Of Biomedical Materials, 4, 255 - 260; f) M. Todo, T. Takayama, 2011. Fracture Mechanisms of Biodegradable PLA and PLA/PCL Blends. Biomaterials - Physics and Chemistry, Prof. Rosario Pignatello (Ed.), ISBN: 978-953-307-418-4, InTech.

5]N. Noroozi, L. L. Schafer, S. G. Hatzikiriakos, 2012. Thermorheological properties of poly ( $\varepsilon-$ caprolactone)/polylactide blends. Polymer Engineering And Science, 52, 2348-2359.

6] a) L. Wang, W. Ma, R.A. Gross, S.P. McCarthy,1998.Reactive compatibilization of biodegradable blends of poly(lactic acid) and poly( e-caprolactone). Polymer Degradation And Stability, 59 ,. 161-168; b) F. Tuba, L. Oláh, P. Nagy,2011.Characterization of reactively compatibilized poly(D,L-lactide)/poly(e-caprolactone) biodegradable blends by essential work of fracture method.Engineering Fracture Mechanics, 78, 3123-3133; c) T. Takayama, M. Todo, H. Tsuji, K. Arakawa, 2006. Effect of LTI content on impact fracture property of PLA/PCL/LTI polymer blends. Journal Of Material Science, 41 , 6501-6504. 
7]A.E. Hafeman, K.J. Zienkiewicz, A.L. Zachman, H.J. Sung, L.B. Nanney, J.M. Davidson, S.A. Guelcher, 2011. Characterization of the degradation mechanisms of lysine-derived aliphatic poly(ester urethane) scaffolds. Biomaterials, 32 , 419-429.

8]R. L. Bagley, P. J. Torvik, 1986. On the fractional calculus model of viscoelastic behavior. Journal of Rheology, 30, 133-155.

9]T. Pritz, 1996. Analysis of four-parameter fractional derivative model of real solid materials. Journal of Sound and Vibration, 195, 103-115.

10]T. Pritz, 2003. Five-parameter fractional derivative model for polymeric damping materials. Journal of Sound and Vibration, 265, 935-952.

11] a) K. S. Cole, R. H. Cole, 1941. Dispersion and absorption in dielectrics I. Alternating current characteristics.The Journal of Chemical Physics, 9, 341-351; b) R. H. Cole, D. W. Davidson, 1950. Dielectric relaxation in glycerine.The Journal of Chemical Physics, 18, 1417; c) S. Havriliak, S. Negami, 1966. A complex plane analysis of $\alpha$-dispersions in some polymer systems.Journal of Polymer Science: Part C, 14, 99-117.

12]a)G.C. Berry, T. Fox ,1968. The viscosity of polymers and their concentrated solutions. In: Fortschritte der Hochpolymeren-Forschung. Advances in Polymer Science, vol 5/3.Springer, Berlin, Heidelberg; b) T.Takayama, M.Todo, 2006. Improvement of impact fracture properties of PLA/PCL polymer blend due to LTI addition. Journal of Materials Science, 41, 4989-4992. 13] a) J. Kolarik, 1996. Simultaneous prediction of the modulus and yield strength of binary polymer blends. Polymer Engineering And Science, 36, 2518-2524; b) J. Kolařk, 1998. Simultaneous prediction of the modulus, tensile strength and gas permeability of binary polymer blends. European Polymer Journal, 34, 585-590; c) J. Kolarik, L. Fambri, A. Pegoretti, A. Penati, 2000. Prediction of the gas permeability of heterogeneous polymer blends. Polymer Engineering \& Science, 40, 127-131; d) J. Kolařík, 1996. Evaluation of the extent of interfacial debonding in polymer blends. Polymer37, 887-891; e) A. Ostafinska, I. Fortelny, M. Nevoralova, J. Hodan, J. Kredatusova, M. Slouf, 2015. Synergistic effects in mechanical properties of PLA/PCL blends with optimized composition, processing, and morphology. RSC Advances, 5, 98971-98982; f) T.Vacková, M. Slouf, M. Nevoralová, L. Kaprálková, 2012. HDPE/COC blends with fibrous morphology and their properties. European Polymer Journal, 48, 2031-2039. 14]M.Rubinstein, R. H.Colby, 1988. Self-consistent theory of polydisperse entangled polymers: Linear viscoelasticity of binary blends. Journal of Chemical Physics,89, 5291-5306.

15] a) N. Najafi, M.C. Heuzey, P.J. Carreau, 2012. Polylactide (PLA)-clay nanocomposites prepared by melt compounding in the presence of a chain extender. Composites Science and 
Technology,72, 608-615; b) A. P. Mathew, K. Oksman, M. Sain, 2005. Mechanical properties of biodegradable composites from poly lactic acid (PLA) and microcrystalline cellulose (MCC). Journal Of Applied Polymer Science 97, 2014-2025. 